\title{
POR UMA OUTRA JUSTIÇA: DIREITO PENAL, ESTADO E SOCIEDADE ${ }^{1}$
}

\author{
Daniel dos Santos
}

\begin{abstract}
RESUMO
As relações entre a sociedade e o Estado nas sociedades contemporâneas constituem o objetivo deste trabalho, em particular o papel do Direito e da Justiça penais. Adaptando uma perspectiva interdisciplinar (Filosofia, Sociologia e Antropologia jurídicas) e normativa, toma partido - como uma possibilidade, sem excluir outras - pela democratização da "democracia”, opondo, para tanto, a socialização do exercício do poder político à "estatização" da sociedade. Mais concretamente, apresenta a Ética do Outro em contraposição à Ética do Um, em que a primeira representa a alteridade, que deve ser incorporada em nossos padrões de conduta, e a outra representa o confinamento em nossos valores particularistas. Além disso, o Direito Penal é percebido como um locus privilegiado em que esses temas - éticas do Outro e do Um, socialização do poder, estatização da sociedade - aparecem relacionados e materializados.
\end{abstract}

PALAVRAS-CHAVE: sociedade; pluralismo; Estado; Direito; Justiça Penal; democracia.

\begin{abstract}
O governo não deve acabar quando o crime acaba, pela falta de objetos sobre os quais realizar sua função?

O poder dos senhores existe não somente devido ao mal, mas também pelo mal. A violência é empregada para mantê-lo e toda violência gera criminalidade. Soldados, policiais e carcereiros, espadas, porretes e correntes são instrumentos para infligir a pena e toda inflição de pena é, por essência, injusta. O Estado emprega as armas do mal para subjugar o mal e é contaminado da mesma forma pelos objetos sobre os quais age e por meio dos quais opera. A moralidade não pode reconhecê-lo, pois a moralidade, sendo simplesmente uma expressão da lei perfeita, não pode dar apoio a nenhuma coisa que cresça fora dessa lei, que subsiste somente pelas violações que nela pratica. É por isso que a autoridade legislativa não pode jamais ser moral-deve ser sempre apenas convencional.
\end{abstract}

SPENCER (1993 [1850], p. 18-19).

\section{TODO UM MUNDO}

Recusamo-nos a crer no "fim da história" e no esgotamento da imaginação, o que nos levaria a acreditar na impossibilidade de renovação das nossas sociedades. Pelas considerações que propomos, queremos suscitar o debate sobre a necessidade urgente de efetuarem-se transformações sociais importantes, mas sobretudo de pensá-las democraticamente. Cremos que as relações entre a sociedade e o Estado devem ser consideradas como seu principal objeto, em particular o papel assumido pelo Direito, sobretudo o Direito Penal. Pretendemos, assim,

\footnotetext{
1 Tradução de Cecília Campello do Amaral Mello (camello@momentus.com.br).
}

pôr em evidência as lógicas que sustentam as relações sociais apresentadas como a Ética do Um e a Ética do Outro. O sentido dessa mudança é o da socialização do Estado e do Direito (Penal), que é entendida como o resultado não somente da interação cotidiana dessas duas éticas, mas também da importância que a Ética do Outro deve assumir no contexto da globalização. A democratização da democracia só é possível com a transformação da relação entre essas duas lógicas, isto é, reconhecendo e fortalecendo o pluralismo nas esferas econômica, social, cultural e, sobretudo, na jurídico-judiciária.

Nossa moral moderna é simples. Há, de um lado, os "bons" e, do outro, os "maus". Ainda que aparentemente isso conforte os nossos espíritos e os das nossas ordens estatais 
democráticas ou ditatoriais, a situação social, econômica e, às vezes, política mais complexa não pára de degradar-se. Ela atinge atualmente proporções "alarmantes e consideráveis", se pensarmos nas conseqüências das guerras assassinas que grassam no planeta e na extensão do fenômeno da exclusão social. O mundo que aí se prende desmorona-se de maneira rápida, gerando, em princípio, uma esperança legítima, mas, logo em seguida, uma decepção desmobilizadora e um temor difícil de suportar. Por outro lado, os valores morais subjacentes a essa representação do "nós" e do "eles" parece não haver mudado. Enquanto comemorava-se a vitória das democracias liberais representativas "nós, os bons" - sobre as ditaduras comunistas e sobre os regimes políticos originados das lutas de libertação nacional no Terceiro Mundo - "eles, os maus" - parecia-se ignorar o fato de que a ordem que acabara de desabar só existia porque repousava sobre essa própria dualidade. Em outras palavras, isso representava a urgência não somente de mudanças importantes no nível da estrutura e da ordem sociais das formações "más", mas também a necessidade de repensar-se e de transformar as formações sociais "boas" (WALLERSTEIN, 1991, p. 1-15).

As forças sociais antes mobilizadas para a mudança parecem enfraquecidas atualmente. Algumas renunciam, em uma atitude de resignação, de derrota e de espera; outras elaboram um discurso e uma ação normalizadores tendendo a justificar os piores desvios dos objetos formais das democracias políticas representativas, agora erigidas em modelo único e final. A ganância, o egocentrismo individualista e a atração do ganho fácil e rápido; a patronagem, a corrupção e outros ilegalismos instalam-se como valores concretos do movimento de globalização, a tal ponto que, face ao retraimento e, em certos casos, à ausência de uma atribuição democrática de prestar contas, até mesmo a Interpol demandava abertamente, em 1994, a moralização dos Estados e dos assuntos econômicos internacionais.

Esse caráter contraditório das transformações iniciadas nos anos 1980 parece-se cada vez mais com um círculo vicioso, uma vez que cidadãos e dirigentes parecem girar em torno si mesmos. A exacerbação dos nacionalismos estreitos, a aparição de uma nova classe de ricos nos países recentemente "democráticos" - às custas da maioria esmagadora das populações, de guerras fratricidas monstruosas, tanto em sociedades do Terceiro Mundo (sobretudo na África e na Ásia) quanto no próprio Ocidente (no Cosovo e na Tchetchênia) - e a globalização dos comportamentos criminais - em particular dos grupos de crime organizado, dos estados e das grandes empresas - chegaram a um momento em que o modelo econômico e social da primeira modernidade encontra-se em pane e o da segunda modernidade ainda não está claramente definido e regulado. Não é suficiente lançar um novo motea nova economia - para que tudo seja repentina e maravilhosamente clarificado. Apesar da ilusão de criação de um só mundo, uma tal situação somente amplia a imagem enganosa de dois mundos separados e cada vez mais distantes.

Depois de 1968, o capitalismo passou de um período de capitalismo "social-democrata" de inspiração keynesiana - durante o qual o Estado e a sociedade civil eram encarados de maneira distinta - a um outro período de capitalismo mundial, cada vez mais integrado, em que o retraimento ou a "submissão" da sociedade ao capital tem por primeira conseqüência a ausência, ao menos aparente, de distinção entre o capital, o Estado e as sociedades civis (SURIN, 1994, p. 927).

Para alguns, essas mudanças encontram suas raízes nas condições históricas concretas do desenvolvimento do capitalismo e nas formas de oposição e de resistência da classe operária e dos atuais "condenados da terra" (Frantz Fanon), enquanto, para outros, o fundamento dessa transformação é, antes de tudo, filosófico: a dialética hegeliana e a noção de contradição retomadas por Karl Marx - que marcaram a passagem do século XIX ao século XX - deixam pouco espaço à singularidade, à multiplicidade e à diferença (versão moderada) ou constituem a própria negação das últimas (versão radical do pósmodernismo).

Porém, tanto uns quanto outros estão de acordo ao afirmar que este período do capitalismo caracteriza-se pelo fato de que o capital opera cada vez mais em um domínio em que a separação entre Estado e sociedade não pode mais ser mantida. Essa tendência organizar-se-ia de modo que haja apenas um único conjunto englobando o Estado e a sociedade.

Entretanto, e apesar do papel da reprodução social, encontramos nas sociedades civis 
manifestações de dúvidas e interrogações sobre as possibilidades de prolongamento dessa tendência. Vemos aparecer aqui e acolá sinais de desilusão a propósito da instrumentalização da sociedade política (o Estado, seus aparelhos e suas instituições) em proveito de um grupo social particular, o capital, e falta de ímpeto para a extensão da democracia às outras esferas da sociedade. Se a globalização refere-se, antes de tudo, ao mundo material da economia e das finanças, ela toca, contudo, todas as esferas das sociedades, inclusive a da globalização das sociedades civis e da formação de uma nova consciência social, política e moral. A constituição de um mundo em rede não é mais privilégio dos dominantes e poderosos.

Enquanto deixamo-nos crer na idéia de que há, por um lado, uma separação entre o "Norte" e o "Sul" e, por outro, entre o Estado e as sociedades civis, a mundialização torna-se um movimento de globalização totalizante, ao menos em seus contornos e pretensões atuais. Esse "deslize" totalitário pode conduzir, sob a cobertura da democracia representativa, a uma ditadura concreta, isto é, à hegemonia total do capital, à imposição dos seus projetos e interesses ao Estado e em grande medida às sociedades civis. O pensamento único manifesta-se, assim, não como um pensamento em voga ou passageiro, mas como uma ideologia dominante singularmente única detentora da verdade verdadeira. A diferença e a disputa - o "différend" segundo Lyotard (1983) -, seriam percebidas como elementos perturbadores a serem desqualificados. Parece-nos, portanto, necessário - à luz da globalização - redefinir as relações entre a sociedade e o Estado partindo das "singularidades, das multiplicidades, das diferenças e das disputas" que povoam as sociedades reais e repensar o projeto democrático, aquele de uma sociedade em busca de maior justiça social, de respeito aos direitos da pessoa humana em uma perspectiva pluralista e de um Estado democrático de Direito.

À primeira vista, as sociedades políticas ocupam um lugar cada vez maior na definição dos meios e objetivos da vida em sociedade. A vida "democrática" é freqüentemente deixada de fora das grandes correntes e da maioria dos grupos sociais que caracterizam a diversidade, a fragmentação e o pluralismo das sociedades civis (os povos e suas instituições). Atualmente, sob a cobertura da legitimidade dos novos blocos históricos dominantes, a democracia no Sul impõese ao conjunto social pela força bruta dos aparelhos estatais, do exército e, sobretudo, da polícia e da coação externa. No Norte, reconhecemos a dominação de uma força particular: o direito, tal como definido e aplicado pelos aparelhos estatais (o Legislativo e o aparato de justiça com suas diferentes instâncias). Que se trate de uma situação fundadora ou das condições de exercício da democracia, a violência, tanto dos estados fracos como dos estados fortes, permitenos observar que as sociedades civis encontramse relegadas a um papel secundário. As grandes empresas, particularmente as transnacionais ou globais, o Estado e seu Direito são os atores principais.

O que acabamos de descrever de modo bem sucinto constitui o contexto global da "aldeia" que habitamos e a que devemos referir-nos. Esse "modelo único e final" de democracia tornou-se uma "coisa" exportável, com todas as desventuras e elementos que aí se anexam: constituições-chave em mãos, acadêmicos especialistas, quadros políticos, consultores de toda espécie; instituições e novas tecnologias, mas também - e não menos importante - a ajuda financeira para o fortalecimento institucional das "novas democracias", lembrando que os pilares da democracia formal e representativa são o mercado livre, o Estado de Direito e a institucionalização dos direitos humanos; a formação policial, que não mais se limita ao treino acadêmico, mas que inclui a transposição de modelos de polícia que "parecem funcionar", da tolerância zero à polícia comunitária; a reestruturação das forças armadas, da educação e formação ao armamento; e o direito, cuja globalização parece se resumir a uma luta entre sistemas ou tradições normativas "ocidentais", Common Law e Direito Romano (GUÉNAIRE, 2000, p. 48-72). Tal atitude ignora completamente o pluralismo jurídico e muito particularmente nega um estatuto ao Direito costumeiro enquanto ordem jurídica. No "melhor" dos casos institui a sua ordenação escrita, positiva e objetiva, retirando-lhe o seu carácter histórico e o seu valor sociocultural.

Essa exportação não se faz sem problemas. $\mathrm{O}$ exemplo da África é talvez extremo, mas bem real. As conseqüências da virada democrática atinge aí proporções que beiram a catástrofe absurda. 
Calculando por baixo, nos últimos dez anos, mais de três milhões de africanos e africanas aí perderam suas vidas. Do ponto de vista social e econômico, os regimes políticos "democráticos" africanos não fazem melhor que aqueles do partido único. Entretanto, algo mudou: eles são em sua maior parte designados hoje como estados em período de transição democrática, pretendentes ao Estado de Direito.

Efetivamente, falou-se muito de ética, de democracia e de Estado de Direito nestes últimos anos e não somente na África. Porém, o discurso que se detém geralmente sobre os três resumese, na maior parte do tempo, a exigir primeiro a presença e a intervenção do Estado, sobretudo pela definição e pela aplicação de novas normas de comportamento aos cidadãos, ao mesmo tempo em que se exige seu desengajamento da esfera econômica e financeira. A possibilidade de mudanças sociais significativas fica, assim, reduzida, porque enquadrada e esquadrinhada por uma multiplicidade de normas jurídicas de Estado às quais se deveriam juntar as normas institucionais, todas pretendendo indicar ao cidadão a "boa" conduta democrática. Isso não faz senão reforçar a posição do Estado e das empresas, "transnacionais" sobretudo, e enfraquecer as distinções ainda possíveis entre o Estado e as sociedades civis.

A norma, neste caso jurídica e estatal, tornase o critério de adesão ao "nós" e de desqualificação do "eles". E a norma penal tem aí um papel central na medida em que se define pelo seu caráter seletivo, repressivo e sobretudo estigmatizante. Este último aspecto permanece como o fato notável do Direito Penal: a passagem da exclusão abstrata à promoção concreta da "degradação na figura social de sua clientela" (BATISTA, 1990, p. 17-26).

Esse processo de integração e de exclusão, dirigido pelo Estado e pelas empresas, mas sobretudo assumido pelo primeiro, levanta questões importantes que se referem fundamentalmente à produção de normas, seu conteúdo, sua linguagem e sua aplicação; às instituições nacionais e, além disso, à "re-invenção" das relações entre a sociedade e o Estado. Se a democracia representativa tornou-se insatisfatória e frustrante, isso se deve provavelmente porque ela aventurouse na via da construção de sua hegemonia, sendo incapaz, hoje, de inovar verdadeiramente e de enriquecer-se, pois isso deveria supor a submissão do Estado à soberania do povo e a extensão dos princípios democráticos ao mundo das relações sociais, econômicas e jurídicas.

Deixando-se corromper material e moralmente, a democracia pode tornar-se facilmente uma ditadura disfarçada - a dos mais fortes. Em um regime democrático, supõe-se que o Direito proteja a sociedade não somente de si própria, mas dos abusos sempre possíveis da sociedade política e dos poderosos. No caso contrário - do controle da sociedade - o Direito torna-se então o instrumento por excelência de legitimação do absolutismo estatal e da dominação do capital.

O campo do Direito Penal parece-nos ilustrar - é claro que de maneira nem sempre evidente esse terreno escorregadio que serve de fronteira entre a democracia e a ditadura. Essa é uma zona "claro-obscura", alimentada por coisas não ditas ou indizíveis, uma linha quase invisível e imperceptível e, no entanto, bem real e cotidiana. É aqui que a sociedade "desarma-se" para ceder espaço, freqüentemente, a uma omnipotência "sacrossanta" do Estado, por meio de um tipo de profissão de fé mais ou menos cega na retidão da autoridade do último. O Estado, em nome da sociedade e por meio do Direito Penal, seleciona os comportamentos que considera nocivos, inaceitáveis ou inadmissíveis (crimes) e as sanções que julga úteis para "puni-los, eliminá-los ou corrigi-los". Ao mesmo tempo, as sociedades civis, os estados, as instituições e as empresas organizam-se concretamente para resolver suas disputas fora do espaço judiciário estatal, onde elas são obrigadas a utilizar regras e ferramentas extraestatais. Evidentemente, isso ocorre freqüentemente e sobretudo quando convém aos atores envolvidos na disputa.

A lei penal visa tanto aos indivíduos quanto aos seus atos, mas estes têm apenas uma existência concreta - passagem do fato ao ato - se os comportamentos assim definidos tornarem-se alvo de reação e de sanções sociais. Pelo seu caráter estigmatizante, o Direito Penal atribui ao "crime" uma utilidade social que pode, caso necessário, permitir a justificação de um aparelho institucional imponente, pesado e custoso, mas bem pouco eficaz quanto se trata de realizar suas próprias finalidades oficiais. Assim, "[...] a Justiça Penal serve menos para proteger a sociedade contra o crime e contra os criminosos do que para dar uma 
satisfação a esta, em detrimento das suas regras e dos direitos dos mais fracos" (LÉVY, 1984, p. 9).

Portanto, é preciso crer que precisamos não apenas de uma simples inovação tecnológica ou de um pequeno ajuste na maquinaria, mas, antes, de algo mais fundamental para o funcionamento das sociedades e, neste momento do sistema mundial e da globalização, para todo o planeta. A essência desse "algo" encontra-se nas modalidades, nos conteúdos e nos meios que cada um de nós escolhe individual e coletivamente, a fim de definir e de determinar a finalidade da nossa vida enquanto seres humanos (indivíduo) e atores (grupo social).

Esta pesquisa permanente do que é essencial e fundamental refere-se, antes de tudo, a uma "situação fundadora", consolidando o passado e colocando em perspectiva um futuro próximo ou distante (FAY, 1982; MAFFESOLI, 1984; KREMERMARIETTI, 1987, p. 3-8). No quadro do Estado de Direito, a lei tem um caráter fundamentalmente contraditório. Por um lado, ela constitui um baluarte contra o arbítrio do Estado e um meio de tornálo imputável e, por outro lado, um meio de controle dos governados sem garantir-lhe a impunidade ilimitada (GIROUX, 1991, p. 17). Charles Pasqua, político francês, Ministro do Interior duas vezes, teria afirmado nas rádios francesas em 1987 que "a democracia termina onde começa o interesse do Estado". Isso corresponde bem ao estado de coisas da democracia atual, mas caracteriza também o pendor escorregadio que nos pode levar ao absolutismo estatal (RUSSBACH, 1987, p. 9). Ora, em uma democracia, o Estado democrático de Direito é responsável diante da sociedade tanto moral quanto juridicamente.

A Ética não se reduz apenas aos valores impostos como essenciais para a sociedade política. A pretensão da última a monopolizar-se, decorrente da usurpação da soberania da Nação, é incompatível com a democracia e com o Estado democrático de Direito, uma vez que a busca desse monopólio afirma a supremacia e até mesmo a hegemonia da sociedade política sobre o conjunto social $^{2}$.

\footnotetext{
2 Incluímos aí tudo que diz respeito à sociedade política: o Estado (aparelho administrativo) e suas instituições, as instâncias executiva, legislativa e judiciária, assim como os partidos políticos e os "aparelhos de Estado".
}

A Ética refere-se, atualmente, à exigência de redefinição de um princípio diretor, o "bem supremo" 3 , fundado sobre a natureza e os valores da consciência moral - apresentada como uma prioridade e um ponto de referência - e sobre a relação entre os deveres e os direitos dos cidadãos e das cidadãs e das instituições. Contudo, não se deve confundir a Ética com a nomenclatura e a enumeração desses deveres e direitos nem com o conjunto dos enunciados de regras processuais determinando sua aplicação. O primeiro aspecto que se refere à sua essência fundadora, mais global e mais larga, situa-se no nível ontológico (Ética Geral). Ele guia, é claro, o segundo aspecto, mais pragmático e específico, que deve se remeter à práxis social, isto é, à organização do mundo concreto das relações sociais (Ética Normativa).

\section{UM MUNDO E DUAS FACES}

O confisco da autonomia das sociedades civis pelo Estado, a emancipação deste e a institucionalização e a burocratização da Ética constituem obstáculos importantes ao processo de democratização da sociedade. O Direito estatal, e particularmente o Direito Penal, parece confundir-se com a Ética do Um. Trata-se de um conjunto de valores determinados apresentandose como um todo estruturado, assumindo as formas de um discurso e de uma ordem fundados, do ponto de vista externo, sobre "processos de exclusão" cujo caráter essencial é o de erigiremse como critério da "vontade de verdade", senão da própria verdade, e que mascaram a "prodigiosa maquinaria destinada a excluir". Do ponto de vista interno, esse discurso e essa ordem referem-se também a um conjunto de "princípios de classificação, de ordenamento e de distribuição" que visam à anulação do acaso em nome da coerência (FOUCAULT, 1971; DACUNHACASTELLE, 1996; VIGNAUX, 1996).

$\mathrm{Na}$ medida em que respondem a interesses específicos - nem sempre com o espírito de conciliação dos interesses diferentes e divergentes que povoam os indivíduos, as classes sociais e as instituições -, as representações estatais da realidade social são necessariamente imperfeitas

\footnotetext{
3 O "bem supremo" não equivale a um objeto natural ou positivo, mas antes a um objeto construído socialmente, isto é, resultado de um exercício democrático e nacional.
} 
e incompletas, às vezes enviesadas. Mas certamente essas representações têm a seu favor a força e a coação, o que permite à Ética do Um impô-las como únicas e verdadeiras. A Ética do Um reivindica para ela mesma a interpretação do verdadeiro (Ética Geral) e o estabelecimento pelo Estado dos princípios e modalidades de sua aplicação (Ética Normativa). Ela identifica-se com o "nós".

A Ética do Outro apresenta-se como um discurso mais disperso, menos estruturado e menos totalizante. Tendo a sociedade como referente, ela deve conjugar a consciência e os interesses individuais com a consciência e os objetivos coletivos. Ela é, portanto, forçada à busca de uma consciência moral, social, mas também nacional e humana, permitindo aos cidadãos e às cidadãs orientar seu comportamento e escolher os meios que lhes convêm para atingir seus objetivos.

Seja no nível da Ética Geral, seja no da Ética Normativa, a Ética do Outro tem contornos menos precisos, ao menos em aparência, pois ela é antes de tudo plural, isto é, composta de elementos múltiplos (ordens jurídicas não-estatais) e independentes de uma realidade fixa e absoluta. Ela é também pluralista, já que a totalidade, caracterizada pela diversidade interna, não é a soma das individualidades, mas, antes, sua articulação e sua relação. A força e a coação ainda existem, mas elas são mais "difusas, divisíveis e invisíveis", o que permite uma iniciativa mais centrada sobre a mediação, a negociação e a conciliação, enquanto a Ética do Um vê aí somente exceções, escolhidas por ela mesma. A Ética do Outro identifica-se com o "eles". Numerosos autores influenciaram nossa construção conceitual a propósito do Um/Uno e do Outro/Outros (LARUELLE, 1986; SERRES, 1991; AUGÉ, 1994; DERRIDA, 1994; 2003; DUFOURMANTELLE \& DERRIDA, 1997; BLANCHARD \& BANCEL, 1998; SCHNAPPER, 1998; SEFFAHI, 1999), pelo que nunca me poderia considerar como pertencendo a uma filiação teórica determinada. No entanto, um autor conta mais do que os outros. Refiro-me ao trabalho, que considero na verdade extraordinário, do autor polonês Ludwik Stomma (1986, p. 13-39), e no qual nós e eles, um e outro(s) são contraditórios e complementares, inseparáveis como em um jogo de espelhos.

Situado nesse contexto e por sua própria natureza, o sistema penal, do Direito à Justiça
Penal, apresenta-se "[...] como se a própria letra da lei não mais pudesse ser autorizada, em nossa sociedade, senão por um discurso de verdade" (FOUCAULT, 1971, p. 21). Entretanto, essa independência fictícia deve ser encarada como um problema que, a nosso ver, situa-se no nível das características próprias ao Direito Penal, em particular o fato deste ser um sistema de exclusão e estigmatização e da tendência atual de recorrer a uma juridicidade penal excessiva como meio de controle das sociedades civis ${ }^{4}$. Essa juridicidade monística é um elemento estratégico importante da relação atual entre o Um e o Outro. No entanto, esse movimento não está desprovido das contradições e mal-estares que afetam a sociedade política e as sociedades civis.

Seria essa tendência reveladora de uma instrumentalização crescente do Direito Penal ao simples serviço das finalidades do Estado, das empresas e do movimento da globalização, sobretudo quando o Estado usa como argumento seu direito de confiar a si próprio o monopólio da defesa da sociedade (HAARSCHER, 1988, p. 127$135)$ ?

Na democracia atual, o discurso da sociedade política apresenta o Direito Penal como sendo uma exceção, quando de fato o Direito Penal deve vigiar e fiscalizar o espaço social como se ele fosse absolutamente necessário para obrigar a sociedade civil a respeitar as exigências democráticas encarnadas pelo Estado. Em nome da sociedade, o Estado transforma a ética e a Justiça Penal como um escudo que o protege das sociedades civis, sendo estas encaradas como potencialmente perigosas ou como fator de risco.

\section{UM MUNDO, DUAS FACES E MÚLTIPLOS ROSTOS}

O Estado democrático do final do século XX encontra-se em uma situação embaraçosa, para não dizer contraditória, pois ele instalou-se como

\footnotetext{
4 Os exemplos dessa tendência encontram-se em muitos países, relacionados a fenômenos tão diversos como a violência conjugal, a delinqüência juvenil, a economia "subterrânea", a prostituição, a droga, o tabaco etc. - e, nos dias de hoje, a implantação do "Estado de Direito" nos países do Terceiro Mundo, freqüentemente com a organização estatal do Direito costumeiro, como já assinalamos.
} 
juiz e parte interessada, como árbitro e não como mediador e conciliador. A democratização do Direito e da Justiça Penal implica a socialização do Estado e não a estatização da sociedade. Ao pluralismo social deve corresponder um pluralismo jurídico concreto que não é exclusivamente aquele das ordens jurídicas do Estado, mas também um reconhecimento dos "mecanismos e engrenagens múltiplas, das relações de autoridade e de força que criam, modificam, aplicam, fazem respeitar as normas jurídicas" (ROMANO, 1975 [1946], p. 10) das sociedades civis e sua capacidade em resolver as situações-problema. As soluções do Outro não são nem menos válidas que aquelas do Um, nem mais onerosas (LANDREVILLE, BLANKEVOORT \& PIRES, 1980).

Essa democratização é uma condição necessária, mas não única para ultrapassar a situação atual. Entretanto, ela não pode fazer-se sem que se reconheça e estabeleça a Ética do Outro, e sua importância, como princípio diretor e fundador da organização social concreta. As normas jurídicas penais e o Direito estatal não são eticamente neutros.

A Ética do Outro pressupõe também o desenvolvimento da noção de justiça social e econômica e a necessidade da confrontação de valores, como condições de uma democratização e de uma socialização do direito e da justiça penais, daí a necessidade de reverter-se a tendência de o Estado criminalizar quase tudo e punir severamente o que é criminalizado. Como afirma A. Pires (1991, p. 51), “[...] nós devemos abandonar a idéia de que a punição penal é um imperativo categórico ou uma necessidade social e que os objetivos que ela persegue somente podem ser atingidos pela aplicação das penas clássicas (pena de morte, prisão e multa penal) [...]”.

Outro problema que se apresenta refere-se ao papel desempenhado pela sociedade política. Ela apresenta-se como guardiã e repositária da soberania, o que lhe confere um estatuto à parte. Em nome da sociedade, como outrora fazia o rei soberano, ela dota-se de meios (as leis e a força) para impor às sociedades civis os valores e a organização de uma consciência moral, que lhe permitem autoproclamar-se árbitra das situaçõesproblema que o Direito Penal estatal designa como infrações, delitos ou crimes.

Sua posição é reforçada pelo estabelecimento do princípio segundo o qual somente o Direito e as instituições estatais constituem "verdadeiras ordens jurídicas". Ao pluralismo das sociedades civis, o Estado responde por um tipo de "pluralismo interno" (a multiplicação, a divisão e a compartimentação das ordens jurídicas estatais) como meio de enquadrar o máximo de espaço social, ao mesmo tempo esforçando-se por manter uma certa unidade e conformidade e preservar as possibilidades de exceção, segundo sua própria definição do tempo e do espaço, isto é, o momento e o lugar escolhidos pelo Estado. Ele exclui, logicamente, o pluralismo extra-estatal.

O pluralismo assim criado é artificial: “[...] o Direito Penal, por destacado que seja, diz respeito, de fato, a todas as classes de fenômenos jurídicos" (KREMER-MARIETTI, 1983, p. 108-109). Existe, em cada ramo do Direito estatal, um detalhe de natureza repressiva do Direito Penal. A diferença - usada como argumento para distinguilo das outras formas de Direito positivo - é aquela que consiste em apagar a individualidade da parte lesada e em identificá-la com o todo social, representado pelo próprio Estado.

Isso tem implicações no nível das sanções, da escolha das sanções repressivas e da recusa quase sistemática em se recorrer a um leque maior e mais diversificado de sanções, mas sobretudo de "sanções reparadoras". Aqui, também, não se deve crer que a Ética do Um é absoluta. Ela é por vezes forçada a conciliar-se com a Ética do Outro, que se exprime pelos movimentos sociais e pela reivindicação dos direitos de resistência e de oposição (GOYARD-FABRE, 1982; PIRES \& VALIÈRES, 1987, p. 80-82; RUSSBACH, 1987; SPENCER, 1993 [1850]), como o exprime a introdução, já há alguns anos, de penas alternativas e de trabalhos comunitários. Contudo, como assinala A. Pires, a tendência geral é ainda de concentrar-se "sobre a justificação e os limites das 'penas duras', negligenciando, primeiramente, as outras sanções correntes em Direito criminal (a prisão, a multa, a condicional, os trabalhos comunitários) e deixando, em seguida, ainda mais radicalmente fora do campo, a questão do recurso a outras sanções e regras correntemente aceitas e integradas em outros setores da vida jurídica" (PIRES, 1991, p. 52).

A Ética do Um carrega consigo a "teologização" do Direito Penal positivo, recorrendo a um deontologismo por vezes exagerado, em detrimento justamente da Ética pura e simples, sobre- 
tudo ao levar-se em conta o fato de que a pena jurídica é apresentada e definida como um castigo, exigindo, assim, um culpado a qualquer preço.

Vale a pena lembrar que na sociedade moderna não há uma só ordem jurídica, mas a coexistência de uma pluralidade de ordens jurídicas, cada ordem podendo, por sua vez, compor-se de esferas jurídicas múltiplas às quais corresponde um sistema de discursos e de valores. Assim, “[...] conceber o Estado simplesmente como uma das formas da sociedade humana, seja ela a mais evoluída, sem por isso the reconhecer uma divindade - algo aliás recusado às outras sociedades de ontem e de hoje - obriga-nos a considerar estas outras ordens como sendo nem mais nem menos jurídicas que a ordem estatal [...]. Pode-se perfeitamente conceber o direito sem o Estado, mas é impossível definir o Estado sem se recorrer ao conceito de Direito" (ROMANO, 1975 [1946], p. 81).

O Direito é um antecedente do Estado, mas o sistema penal como tal é uma produção do Estado e permanece, sobretudo em uma democracia política, como um elemento contraditório. Sem dúvida, ele não é sempre a expressão pura e simples dos interesses de uma classe social dominante ou dirigente ou o produto direto da Ética do Um. Do mesmo modo, não podemos pretender ingenuamente que ele é a expressão original do direito autêntico, legítimo e indiscutível. Isso equivaleria à atribuição de uma essência suprasocial ao poder estatal (o Legislativo e o Judiciário) e à estrutura burocrática (aparelho de Justiça Penal) de que o Estado serve-se para aplicar a lei penal.

Logo, confundir o Direito e a lei (norma jurídica do Estado) pertence, de saída, primordialmente, ao domínio ideológico do Estado. Dada sua posição central na confirmação e na configuração da ordem jurídico-política, o discurso próprio à Ética do Um refere-se às contradições, quando existem, como um fato de importância menor na medida em que o Estado "responde" à vontade geral do povo. O que o Estado faz e promulga - o Direito e a lei penais - deve ser percebido como juridicamente legítimo e autêntico. Ele encarna a verdade. Não há direito além ou abaixo de suas leis.

Esse discurso está tão fixado em nossos espíritos como um elemento crucial da nossa estrutura mental que se tornou falacioso em alguns momentos. Ousar questionar a noção de crime, um debate que se estende desde o século XIX, torna-se uma condição necessária para o desenvolvimento da relação de face-a-face entre as duas éticas. Juristas, antropólogos, sociólogos e filósofos do Direito encontram-se confrontados com um problema idêntico quando procuram a essência de uma ordem jurídica: que é o Direito?

\section{FACE-A-FACE}

Hoje em dia, a oposição entre a Ética do Um e a Ética do Outro é bem real e concreta, caracterizada por um movimento que tem a sua dinâmica própria. Entretanto, não se trata de uma relação do Um com o Outro, mas de um face- $a$ face, cuja finalidade não poderá ser a integração das duas nem a submissão do Outro ao Um: "Se pudéssemos possuir, apreender e conhecer o outro, ele não seria o outro. Possuir, conhecer, apreender são sinônimos de poder" (LEVINAS, 1989, p. 19, 83).

Por esse processo de negociação, de mediação e de compromisso (HUYGHEBAERT \& MARTIN, 2002; LAJOIE, 2002), a Ética do Outro questiona a Ética do Um e interroga a sociedade política e o Direito Penal, levando-nos a repensar a democracia e, sobretudo, a questão fundamental que diz respeito à responsabilidade, à prestação de contas e à sanção: quem é responsável pelo quê, diante de quem e como levar a cabo essa responsabilidade?

Todo Estado reage freqüentemente de maneira arrogante, senão repressiva, aos comportamentos e aos discursos que contestam os seus próprios. Mesmo se ele é capaz de aceitar a reforma e a mudança institucionais, o Estado busca, acima de tudo, preservar o statu quo, sem levar em conta os meios utilizados pelo Outro. Este, porém, desde a ascensão da República, pode e deve reivindicar seu direito de resistir às ordens injustas, imorais e arbitrárias dos que exercem o poder político, bem como seu direito de opor-se às ações do Estado ou de seus agentes que sejam julgadas como contrárias à sua missão primeira: "servir o bem público". Situamo-nos aqui em uma perspectiva contratualista, já que o Direito à oposição está ligado à ruptura ou à violência do pacto estabelecido entre a sociedade e o Estado por este último.

Em uma perspectiva da Ética do Outro, tratase de exigir um reconhecimento sincrônico e diacrônico e uma relação que pode ir da 
confrontação à complementaridade. Ainda que ela possa ir até a rejeição total da Ética do Um, esse não deve necessariamente ser seu objetivo. Assim, parece-nos evidente que o desconhecimento mútuo a que se consagram o Um e o Outro só pode ser favorável ao Um, forçando o Outro à maior ou menor "clandestinidade". Dentre todas as formas de Direito estatal, o Direito Penal talvez desempenhe o papel principal, por sua natureza repressiva, punitiva e estigmatizante e por seu alcance em termos de visibilidade real, mas sobretudo simbólica, aí incluídas as instituições particulares que dele fazem parte - por exemplo, a polícia e a prisão.

Está na competência das sociedades civis "reforçar seus direitos políticos" (cidadania) e não esperar que a sociedade política decida-se a outorgá-los. É, portanto, importante que a primeira crie suas próprias instituições de educação jurídica, que trace suas próprias estratégias e que saia da passividade, desenvolvendo meios específicos. Podemos citar como exemplos a criação de movimentos sociais de defesa, de reivindicação e de afirmação, o recurso mais sistemático, quando necessário, às instâncias da ordem jurídica estatal para exigir a realização dos princípios e dos valores compatíveis entre o Um e o Outro. É preciso “[...] demonstrar juridicamente que o mundo não pertence nem aos estados nem às grandes indústrias, que a ordem das coisas nunca teve nenhum direito - o que é historicamente provado - que a vida não é um assunto dos estados" (RUSSBACH, 1987, p. 10).

Esses direitos à resistência e à oposição são uma exigência ética frente aos limites do poder estatal. Alguns autores vêem-nos mais como verdadeiros direitos da pessoa humana. O Estado outorga-se o monopólio da legitimidade e mantém o Direito Penal como seu refém, já que o último torna-se um conjunto de normas estatais que usam como argumento modelos de comportamento impostos pelo Estado, sob a ameaça de sanções organizadas em nome da sociedade. Estas constituem um ingrediente capital do funcionamento da Justiça Penal. As sanções são medidas que acompanham as leis penais; elas podem ter um caráter coercitivo, referindo-se assim à coação que impõem como resultado ou conseqüência de uma infração, delito ou crime. Elas remetem ao infrator a obrigação de realizar um gesto ou uma ação concreta, julgados suficientes e necessários ao seu perdão. As sanções podem também ter um caráter punitivo. Este implica, além da obrigação que a coerção impõe (contrato forçado), a expiação da infração cometida. Neste caso, a finalidade última da sanção é essencialmente de reprimir e de castigar aquele ou aquela que transgride a lei penal.

A aplicação de sanções faz-se de acordo com regras processuais e por instituições designadas e criadas pelo Estado. Elas situam-se tanto no domínio da Ética Geral quanto no da Ética Normativa quando se trata de definir ou de escolher sua forma e seu conteúdo: quais comportamentos, quais indivíduos, quais grupos ou quais instituições incluir nos seus objetivos? Mas também as modalidades de sua aplicação. Ainda em relação à qualificação da sanção, convém acrescentar que: '[...] a utilização da expressão 'sanção legal' (no lugar de 'pena') destina-se a enfatizar que a noção de obrigação prevalece sobre a de punição. Ela é adotada porque a noção de obrigação compreende a de punição, enquanto a recíproca não é verdadeira. Embora a execução de todas as sentenças seja obrigatória na letra da lei, elas não impõem um grau de privação tal que se possa chamá-las legitimamente de punições" (CCDP, 1987, p. 126).

Portanto, o pluralismo jurídico lembra-nos justamente de que o Direito como produto social deve referir-se e abrir espaço às produções, às pressões e aos discursos múltiplos e singulares que emergem das sociedades civis e que se traduzem pelas ordens jurídicas extra-estatais.

Chegados a este momento, é importante prevenir-nos contra as construções míticas. Elevar a Ética do Outro a um estatuto teológico é tão danoso quanto a dominação da Ética do Um. Os discursos, as pressões e as produções que emergem da sociedade civil não estão isentos de injustiças e de ambigüidades ou livres do caráter repressivo e punitivo. Generalizemos: a sanção não é uma invenção nem do Estado moderno nem do Direito Penal. Referindo-se a dois estudos sobre os Txicào do Brasil e os Achuards da Amazônia equatoriana, Kremer-Marietti nota que, "Nas duas sociedades sem sistema penal nem ordem política, a sanção 'funciona' apesar de tudo [...]. Vemos pois, nos dois casos, agir essa culpabilidade fundamental constitutiva da existência e, em um certo caso, vemos que ela é até mesmo fundadora, do ponto de vista do poder político" (KREMER-MARIETTI, 1983, p. 111). 
O exemplo citado permite-nos estabelecer um universal que tem pouco valor, já que se constrói ao preço de uma generalização tal que termina por esconder o que há de particular e singular no Direito Penal e na sanção. É justamente tal singularidade que nos convida a crer que é imperioso estabelecer um face-a-face da Ética do Um com a Ética do Outro, mais que procurar os fundamentos legitimadores - e não necessariamente legítimos - de sua supremacia.

\section{PLURALISMO(S) E SÍNTESE(S)?}

O Direito deve, antes de tudo, indicar os valores libertadores que reafirmam a soberania dos povos que constituem as sociedades civis e as normas que regem a emancipação social e não a emancipação do político. A lei representa, então, apenas um episódio dentre outros. Da mesma forma, a responsabilidade e a imputabilidade - no sentido de responsabilidade e de prestação de contas - das instituições estatais que constituem o aparelho de Justiça Penal exigem da última sua socialização, isto é, que a polícia, a prisão e o Judiciário não devem mais responder somente ao Estado, mas às sociedades civis também.

Por um lado, o discurso do Um tem tendência a tornar-se o discurso de uma tecnocracia, com uma linguagem hermética, opaca, calculada e distante, cujo objeto principal não é aproximar-se do Outro e estabelecer com ele trocas frutíferas (CÁRCOVA, 1998). Ao contrário, esse discurso cria um fosso cada vez maior; o Estado vê a sociedade civil como um risco possível e factível, até mesmo como um inimigo que é preciso vigiar, disciplinar e controlar. Aqui, esse discurso situase no interior do que Pires (1991, p.68ss.), referindo-se à análise das reformas penais, intitula o paradigma da "ética total". Por outro lado, o discurso do Outro, menos uniforme, portanto, mais fraccionado, identifica-se com o paradigma da "ética compreensiva". Face à necessidade de socialização das instituições da justiça, este discurso reivindica a democratização.

Certos pesquisadores (BARATTA, 1985) preconizam a redução do Direito Penal àquilo que chamam de "Direito mínimo", limitando, assim, o alcance e a intensidade do Direito e da Justiça penais estatais. Os direitos humanos tornam-se, então, um ponto de apoio para criticar-se o Direito Penal. O movimento abolicionista (HULSMAN \& BERNAT DE CELIS, 1987) vai ainda mais longe, na medida em que crê que o tratamento jurídico das situações-problema não tem necessidade, via de regra, do "estilo penal" de resolução dos conflitos. Além disso, o Estado "democrático" despende bilhões para reforçar seu dispositivo penal, desenvolvendo a cultura do controle da criminalidade como uma indústria (CHRISTIE, 1993), enquanto permanece extremamente tímido quando se trata de adotar medidas econômicas, sociais e culturais visando a retirar da miséria humana os contestadores, que a ela são submetidos por meio das instituições e normas estatais (por ex.: a questão do regime de emprego e a exclusão social). Por outro lado, o Estado "democrático" faz-se de surdo às reivindicações que se referem a uma redistribuição da riqueza, mais justa e eqüitativa.

Não podemos senão nos regozijar quando alguém como Robert Badinter, advogado e Senador francês, antigo Ministro da Justiça e antigo Presidente do Conselho Constitucional da França, afirma que é preciso, "[...] daqui em diante, resolver um grande número de conflitos (infrações, delitos e crimes) por outras vias que não a justiça, disto estou convencido". E que, apesar da sua defesa apaixonada da justiça francesa,"progressos substanciais estão ainda por fazer, especialmente reforçar as garantias estatutárias dos magistrados, melhorar o processo penal e liberar a justiça dos litígios que podem encontrar sua solução fora dos pretórios" (BADINTER, 1997, p. 7).

O reconhecimento do Outro e do seu lugar passa, prioritariamente, por um quadro analítico que dê conta da pluralidade cultural, individual e coletiva. Essa pluralidade caracteriza-se pela diversidade e pelas distinções que fundam a unidade das sociedades civis - o diferente - e não sua homogeneidade que, contrariamente, é um projeto de sociedade construída sobre a hegemonia de um gênero, de uma raça, de uma etnia ou de uma classe social. Em segundo lugar, esse reconhecimento do Outro supõe a possibilidade de uma criação plural também de valores e de princípios correspondentes aos interesses múltiplos, individuais e coletivos que, enfrentando-se, acabam chegando a um compromisso laborioso. Este seria a expressão da concepção de uma vontade geral que emana da sociedade e não do Estado: "Uma disputa ('différend') seria um caso de conflito entre, pelo menos, duas partes que não pode ser solucionado eqüitativamente, devido à ausência de uma regra de julgamento aplicável às duas argumentações" (LYOTARD, 1983, p. 9). 
A disputa coloca, assim, um problema considerável: por que o Direito Penal estatal não parece integrar a Ética do Outro? Seria isso devido ao fato de que o Estado e o Direito Penal apropriam-se do "conflito"? Se esse é o caso, não se trata mais de uma disputa, mas de um litígio e a intervenção do Estado e do Direito Penal causariam prejuízos ao Outro, ao Um ou ainda a ambos: "as regras do gênero de discurso segundo as quais se julga, não são aquelas do(s) gênero(s) de discurso(s) julgado(s)", acrescenta ainda Lyotard (ibidem). A lei penal deve, assim, tornarse um julgamento aplicável às duas argumentações, isto é, às partes que se enfrentam em um processo penal, de modo a poder-se solucionar eqüitativamente a disputa. Ela deve cessar de ser unilateral para aí incluir o discurso do Outro, ou deixar a possibilidade de resolução das situaçõesproblema fora do seu próprio domínio, o que significa a possibilidade de se escolher "outras" ordens jurídicas, mais abertas às duas partes, como locais e meios mais apropriados à resolução das disputas.

Uma Ética do Outro não pressupõe necessariamente um Direito não-escrito, mas sim um "ponto de referência comum a todas as morais efetivas, como elemento fundador absoluto da pessoa moral, necessário à constituição do sujeito: fora da obrigação moral não há sujeito responsável" (KREMER-MARIETTI, 1987, p. 3-4).

Seu ponto de referência é uma situação fundadora vislumbrada, como mencionamos antes, em uma perspectiva sincrônica e diacrônica da história. Para descrevê-la e compreendê-la, énos preciso recolocar em causa a lógica, a estética e a moral/ética que caracterizam o Um, e cujo objeto foi sempre o de estabelecer sua conformidade às normas reinantes do verdadeiro, do belo e do bem e que conduziram a pensar-se o Estado como uma totalidade absoluta.

As duas percepções históricas mencionadas anteriormente, que nos remetem às categorias analíticas do tempo e do espaço, constituem referências cognitivas importantes para interpretar o que não é demonstrável e para relativizar a totalidade social, desconstruindo-a, isto é, desfazendo essa totalidade e decompondo-a em partes singulares, os Outros. A totalidade social não é mais a soma das partes, mas, antes e em princípio, sua cisão pluralista (contendo várias unidades) e também plural (servindo para destacar o maior número); em seguida, a articulação freqüentemente contraditória da síntese dessa cisão. Não há um sujeito, mas sujeitos instáveis, não apresentáveis, divisíveis e invisíveis (LYOTARD, 1979), que é preciso ressaltar e pôr à luz de maneira a deduzir significações úteis à compreensão, à análise e às explicações possíveis.

É, portanto, necessário romper com o julgamento estético e moral dominante que tem como objeto nossas sociedades e que nos impele a pronunciar-nos em conformidade com as regras preestabelecidas, concebidas como critérios imutáveis e tidas como construções racionais, naturais e universais. Para ultrapassar o que a Ética do Um é segundo essa conformidade, seria, em princípio, mais significativo olhar da perspectiva do "sublime" (Kant), definido ao mesmo tempo como uma "afeição forte e equívoca", dolorosamente insuficiente, portanto, sem forma determinada. $\mathrm{O}$ "sublime" exige a pesquisa e a invenção do paradoxo, do ininteligível fundado sobre a diferença e a imprevisibilidade, sobre aquilo que são as instabilidades que povoam as sociedades.

Desconstruir a totalidade social significa explorar os múltiplos sentidos, domínios e registros que ela contém, interrogar a lógica, a estética e a moral que a fundam e questionar a natureza, a razão de ser e os componentes que a caracterizam. A sociedade, como objeto de pesquisa, define-se sobretudo pela diversidade; cada pesquisador detém elementos preciosos do conhecimento da sociedade, mas, modéstia à parte, relativamente parciais.

Encetar a desconstrução não significa a exclusão sistemática de uma visão de conjunto, nem a ausência de rigor - ao contrário. Ela é condição fundamental para colocar em evidência o caráter múltiplo e diverso, pluralista e plural da sociedade e para dar um sentido harmonioso à Ética do Outro. É preciso considerá-la não como um universo fechado, autônomo e auto-suficiente, mas como contendo uma realidade que é preciso apreender como um mundo aberto, à imagem das sociedades civis e não do Estado.

A Ética do Outro não é transformável em uma norma comum, reguladora e garantidora da ordem jurídico-política, da homogeneização e da uniformização das sociedades civis. O geral e o universal devem abrir espaço ao particular e ao 
singular, e não serem substituídos por eles, coisa que o Estado ignora, uma vez que "determinar $a$ priori o conteúdo dos direitos do homem implica congelá-los arbitrariamente, impedindo o questionamento das regras estabelecidas e a busca de novas regras, interrompendo prematuramente o debate sobre a questão do justo e do injusto, o que significa proscrever a disputa" (LYOTARD \& ROGOZINSKI, 1985, p. 33).

Não temos a pretensão de encerrar um debate que apenas recomeçou e que deve prosseguir vigorosamente. Também não é nossa intenção a busca de um modelo ou de um tipo ideal de justiça futura, como se fôssemos os detentores únicos da "verdade verdadeira". Seria uma "fraude" sem possibilidade de perdão, pois contradiríamos tudo o que acabamos de escrever. Pretendemos, sim, e modestamente, contribuir para uma reflexão teórica e analítica das nossas sociedades contemporâneas que nos parece urgente e necessária, ainda que normativa. Reconhecemos que ela deve ser completada pelo acréscimo das dimensões social, econômica e política, propondo uma direção dentre tantas outras, já que "o que se torna insuportável é a idealização de uma ordem que não reconhece seu próprio arbitrário, porque não pára de criar a ilusão de que ela está sempre o vencendo" (JEUDI, 1993, p. 34).

Delmas-Marty (1991) chama a nossa atenção para o fato de que, tradicionalmente, no Direito e na Justiça penais, tudo apresenta-se sob o signo da coerência, da homogeneidade e da estabilidade, como o exemplo do Código Penal. Porém, quando encaramos o estudo desses objetos e quando lemos os relatórios que se supõe sustentar as reformas, constatamos que a realidade está bem distante disso. À ordem corresponde sempre a desordem, que contém elementos assimétricos, como a incoerência, a heterogeneidade e, sobretudo, a instabilidade - isto é, a vida.

Daniel dos Santos (santos@synapse.net) é sociólogo, Professor de Criminologia na Faculdade de Ciências Sociais da Universidade de Ottawa (Canadá) e Diretor dos Estudos Superiores do Departamento de Criminologia da mesma Universidade.

\section{REFERÊNCIAS BIBLIOGRÁFICAS}

AUGÉ, M. 1994. Le sens des autres. Actualité de l'anthropologie. Paris : A. Fayard.

BADINTER, R. 1997. Justice pour la justice. Le Monde, Paris, 8. fév., Sélection hebdomadaire, p. 7.

BARATTA, A. 1985. Principi del Diritto Penale minimo. Per una teoria dei diritti umami come oggetti e limiti della legge penale. Dei Delitti e Delle Pene, Bari, v. III, n. 3 , p. 443-447, sett.dic.

BARBOSA, L. 1992. Ojeitinho brasileiro. A arte de ser mais igual que os outros. Rio de Janeiro : Campus.

BATISTA, N. 1990. Introdução crítica ao Direito brasileiro. Rio de Janeiro : Revan.

BLANCHARD, P. \& BANCEL, N. 1998. De l'indigène à l'immigré. Paris : Gallimard.

CÁRCOVA, C. M. 1998. A opacidade do Direito. São Paulo : LTR.
CHRISTIE, N. 1993. Crime Control as Industry. Towards Gulags Western Style? London : Routledge.

CCDP. 1987. Réformer la sentence: une approche canadienne. Ottawa : Ministère des Approvisionnements et Services du CanadaCommission Canadienne sur la Détermination de la Peine.

DACUNHA-CASTELLE, D. 1996. Chemins de l'aléatoire. Paris : Flammarion.

DELMAS-MARTY, M. 1991. Pensée moderne et réformes pénales. In : PLANTY-BONJOUR, G. \& LEGEAIS, R. (dir.). L'évolution de la philosophie du droit. Paris : PUF.

DUFOURMANTELLE, A. \& DERRIDA, J. 1997. De l'hospitalité. Paris : Calmann-Lévy.

DERRIDA, J. 1994. Politiques de l'amitié. Paris : Galilée.

.2003. Voyous. Paris : Galilée. 
FAY, J.-P. 1982. Violence. In : Dictionnaire politique portatif en cinq mots. Paris : Gallimard.

FOUCAULT, M. 1971. L'ordre du discours. Paris : Gallimard.

GENARD, J.-L. 2000. Les dérèglements du droit. Bruxelles : Labor.

GIROUX, G. 1991. L'éthique et le droit : convergence ou divergence en démocratie libérale? Cahiers de Recherche Éthique, Rimouski, n. 16, p. 11-28, 3 éme trimestre.

GOYARD-FABRE, S. 1982. Le peuple et le droit d'opposition. Cahiers de Philosophie politique et juridique, Caen, n. 2, p. 69-87. Actes du Colloque "Philosophie et démocratie", Caen, 26-27.mai.1982.

GUÉNAIRE, M. 2001. Droit Romain, Common Law : quel droit mondial? Le Débat, Paris, n. 115, p. 48-72, mai.

HAARSCHER, G. 1988. La raison du plus fort. Liège : P. Mardaga.

HULSMAN, L. H. C. \& BERNAT DE CELIS, J. 1982. Peines perdues. Le système pénal en question. Paris : Le Centurion.

HUYGHEBAERT, P. \& MARTIN, B. 2002. Quand le Droit fait l'école buissonnière. Pratiques populaires de Droit. Paris : Descartes.

JEUDI, H.- P. 1993. L'éloge de l'arbitraire. Paris : PUF.

KREMER-MARIETTI, A. 1983. Les fondements philosophiques du Droit Pénal. In : CHEVALIER, J. (éd.). Le droit en procès. Paris : PUF. . 1987. L'Éthique. Paris : PUF.

LAJOIE, A. 2002. Quand les minorités font la loi. Paris : PUF.

LANDREVILLE, P.; BLANKEVOORT, V. \& PIRES, A. P. 1980. Les coûts sociaux $d u$ système pénal. Montréal : École de Criminologie-Université de Montréal.

LARUELLE, F. 1986. Les philosophies de la différence. Paris : PUF.

LEVINAS, E. 1989. Le temps et l'autre. Paris : Quadrigue.
LÉVY, T. 1984. Le crime en toute humanité. Paris : Grasset.

LYOTARD, J.-F. 1979. La condition postmoderne. Paris : Minuit. 1983. Le différend. Paris : Minuit.

LYOTARD, J.-F. \& ROGOZINSKI, J. 1985. La police de la pensée. L'autre journal, Paris, $\mathrm{n}$. 10, p. 27-34, déc.

MAFFESOLI, M. 1984. Essais sur la violence banale et fondatrice. Paris : Méridiens.

PIRES, A. 1991. Éthiques et réforme du droit criminel : au-delà des philosophies de la peine. Ethica, Rimouski, v. 3, n. 2, p. 47-78.

PIRES, A. \& VALIÈRES, S. 1987. Droits de la personne et information juridique : une recherche évaluatrice. Rapport n. 16. Ottawa : Ministère de la Justice du Canada.

ROMANO, S. 1975 [1946]. L'ordre juridique. Paris : Dalloz.

RUSSBACH, O. 1987. La déraison d'État. Paris : La Découverte.

SCHNAPPER, D. 1998. La relation à l'autre. Au cœur de la pensée sociologique. Paris : Gallimard.

SEFFAHI, M. (dir.). 1999. Autour de Jacques Derrida. Manifeste pour l'hospitalité. Grigny: Paroles d'Aube.

SERRES, M. 1991. Le tiers-instruit. Paris : Gallimard.

SPENCER, H. 1993 [1850]. Le droit d'ignorer l'État. Paris : Les Belles Lettres.

STOMMA, L. 1986. Campagnes insolites. Paysannerie polonaise et mythes européens. Lagrasse : Verdier.

SURIN, K. 1994. Reinventing a Physiology of Collective Liberation : Going "Beyond Marx" in the Marxism(s) of Negri, Guattari, and Deleuze. Rethinking Marxism, New York, v. 7, n. 2, p. 9-27, Summer.

VIGNAUX, G. 1996. Le démon du classement. Paris : Seuil.

WALLERSTEIN, I. 1991. Geopolitics and Geoculture. Essays on the Changing WorldSystem. Cambridge, UK : Cambridge University. 